\title{
O Herpesvírus bovino tipo 5 (BoHV-5) pode utilizar as rotas olfatória ou trigeminal para invadir o sistema nervoso central de coelhos, dependendo da via de inoculação ${ }^{1}$
}

\author{
Diego Gustavo Diel ${ }^{2}$, Erika Toledo da Fonseca ${ }^{2}$, Soraia Figueiredo de Souza ${ }^{2}$, \\ Alexandre Mazzanti ${ }^{3}$, Fernando Bauermann ${ }^{4}$, Rudi Weiblen ${ }^{5}$ e \\ Eduardo Furtado Flores ${ }^{5 *}$
}

\begin{abstract}
Diel D.G., Fonseca E.T., Souza S.F., Mazzanti A., Bauermann F., Weiblen R. \& Flores E.F. 2005. [Bovine herpesvirus $\mathbf{5}$ may use the olfactory and trigeminal pathways to invade the central nervous system of rabbits, depending upon the route of inoculation.] 0 Herpesvírus bovino tipo 5 (BoHV-5) pode utilizar as rotas olfatória ou trigeminal para invadir o sistema nervoso central de coelhos, dependendo da via de inoculação. Pesquisa Veterinária Brasileira 25(3):164-170. Departamento de Medicina Veterinária Preventiva, Universidade Federal de Santa Maria, 97105-900 Santa Maria, RS, Brazil. E-mail: flores@ccr.ufsm.br

Bovine herpesvirus type 5 (BoHV-5) is a major etiological agent of meningoencephalitis in cattle. Following replication in the nasal mucosa, viral invasion of the brain is thought to occur mainly by the olfactory pathway. To address the role of this pathway in the pathogenesis of neurological infection in a laboratory model, 30 days old rabbits had the main olfactory bulbs (MOBs) surgically removed and were subsequently inoculated intranasally (IN) or conjunctivally (IC) with a highly neurovirulent BoHV-5 strain (SV-507). Following IN inoculation, 10 out of 10 (100 \%) control rabbits developed neurological disease. The clinical onset ranged from day 5 to 10 postinoculation (pi, average 7.5 days); nine being euthanized in extremis and one recovering after a mild clinical course. In contrast, only one rabbit $(9.1 \%)$ of the group lacking the MOBs $(n=11)$ developed neurological disease (onset at day $17 \mathrm{pi}$ ). Dexamethasone administration to the survivors $(\mathrm{n}=10)$ at day 50pi was followed by virus shedding in nasal and/or ocular secretions by 8 animals, demonstrating that the virus was able to reach the trigeminal ganglia (TG) during acute infection. These results demonstrate that the olfactory route provides the main, yet not the sole access to the brain of rabbits following IN inoculation. To address the role of a second pathway, groups of control $(n=12)$ or MOB-lacking rabbits $(n=12)$ were inoculated into the conjunctival sac (IC), following which the virus would be expected to use the ophtalmic branch of the trigeminal nerve to reach the brain. Ten control rabbits $(83.3 \%$ ) developed neurological disease upon IC inoculation (onset 15.3 days [11 to 20]). Previous ablation of the MOBs did not affect the frequency and course of neurological disease: ten out of 12 rabbits $(83.3 \%)$ lacking the MOBs developed neurological disease (onset 9 to $15 \mathrm{dpi}$, average: 12.7 days) upon IC inoculation. These results demonstrate that both IN and IC routes may operate in the transport of BoHV-5 to the brain of experimentally infected rabbits, depending on the route of inoculation. IN inoculation results in a fast and efficient transport by the olfactory pathway, the trigeminal route providing an alternative, much slower and less efficient transport; IC inoculation results in efficient viral transport by the trigeminal route, yet with a delayed kinetics comparing to the transport provided by the olfactory pathway.
\end{abstract}

INDEX TERMS: Bovine herpesvirus type 5, BoHV-5, neurological infection, rabbits.

\footnotetext{
1 Recebido em 2 de dezembro de 2004.

Aceito em 3 de fevereiro de 2005.

${ }^{2}$ Mestrando em Medicina Veterinária (UFSM).

${ }^{3}$ Depto Clínica de Pequenos Animais, Universidade Federal de Santa Maria (UFSM).
}

\footnotetext{
${ }^{4}$ Acadêmico do Curso de Medicina Veterinária, UFSM. Bolsista de Iniciação Científica do CNPq.

${ }^{5}$ Depto Medicina Veterinária Preventiva, Universidade Federal de Santa Maria (UFSM), 97105-900 RS, Santa Maria, Brasil. "Autor para correspondência: E-mail: flores@ccr.ufsm.br
} 
RESUMO.- O herpesvírus bovino tipo 5 (BoHV-5) é um agente importante de meningoencefalite em bovinos. Após replicação na mucosa nasal, acredita-se que o vírus invada o cérebro principalmente pela via olfatória. Para investigar a importância dessa via na patogenia da infecção neurológica em um modelo animal, coelhos recém-desmamados (30 dias) foram submetidos à ablação cirúrgica dos bulbos olfatórios (BOs) e posteriormente inoculados pela via intranasal (IN) ou no saco conjuntival (IC) com uma cepa altamente neurovirulenta do BoHV-5 (SV-507). Após inoculação IN, 10/10 coelhos no Grupo Controle (com BOs) desenvolveram enfermidade neurológica, com início dos sinais clínicos entre os dias 5 e 10 pós-inoculação (pi) (média de 7,5 dias); em contraste, no grupo submetido à ablação dos BOs $(\mathrm{n}=11)$, apenas um animal $(9,1 \%)$ desenvolveu doença neurológica (início no dia 17pi). Administração de dexametasona aos animais sobreviventes $(n=10)$ no dia 50 pi resultou em excreção viral em secreções nasais e/ou oculares por oito destes, demonstrando que o vírus foi capaz de atingir o gânglio trigêmeo (TG) durante a infecção aguda. Esses resultados demonstram que a rota olfatória representa a via principal, mas não única, de acesso ao cérebro de coelhos após inoculação IN. Para investigar o papel de uma segunda possível via de acesso, grupos de coelhos controle $(n=12)$ ou submetidos à ablação dos BOs $(n=12)$ foram inoculados no saco conjuntival (IC), após o qual o vírus poderia utilizar o ramo oftálmico do nervo trigêmeo para invadir o cérebro. Dez coelhos controle $(83,3 \%)$ desenvolveram doença neurológica após inoculação IC, com início dos sinais entre os dias 11 e 20 (média 15,3 dias). A ablação prévia dos BOs não afetou a frequiência ou o curso da doença neurológica nesse grupo: $10 / 12$ coelhos $(83,3 \%)$ sem os BOs desenvolveram a doença neurológica, com os sinais iniciando entre os dias 9 e 15pi (média 12,7 dias). Esses resultados demonstram que tanto a via olfatória como a trigeminal podem servir de acesso para o BoHV5 invadir o cérebro de coelhos inoculados experimentalmente, dependendo da via de inoculação. Inoculação IN resulta em um transporte rápido e eficiente pela via olfatória; com a via trigeminal servindo de acesso mais lento e menos eficiente. Inoculação IC resulta em transporte e invasão eficientes, porém mais tardios, provavelmente pela via trigeminal.

TERMOS DE INDEXAÇÃO: Herpesvírus bovino tipo 5, BoHV-5, infecção neurológica, coelhos.

\section{INTRODUÇÃO}

O herpesvírus bovino tipo 5 (BoHV-5) é um alfaherpesvírus associado à meningoencefalite em bovinos (Roizman 1992). Infecção natural e experimental de bovinos jovens com o BoHV-5 resulta em invasão e replicação no sistema nervoso central (CNS), seguida de enfermidade neurológica de curso geralmente fatal. Os sinais clínicos da enfermidade incluem depressão, tremores, opistótono, protusão da língua, salivação, bruxismo, cegueira, ataxia, convulsões (Bagust \& Clark 1972, Carrillo et al. 1983, Beltrão 2000, Meyer et al. 2001, Perez et al. 2002). A infecção e enfermidade neurológica pelo BoHV-5 têm sido relatadas em vários países, porém com uma frequiência maior no Brasil e Argentina (Carrillo et al. 1983, Salvador et al. 1998).
Após a penetração pela via nasal, o BoHV-5 replica na mucosa do trato respiratório superior produzindo sinais respiratórios leves a moderados (Meyer et al. 2001, Vogel et al. 2004). A replicação primária na mucosa nasal pode persistir por mais de 15 dias (Vogel et al. 2004), e freqüentemente é seguida de invasão e replicação viral no sistema nervoso central (CNS), resultando em meningoencefalite não supurativa (Bagust \& Clark 1972, Narita et al. 1976, Beltrão 2000, Meyer et al. 2001, Perez et al. 2002). Os sinais neurológicos geralmente aparecem a partir do dia 9 ou 10 pós-infecção e incluem tremores, bruxismo, salivação, protusão da língua, opistótono, cegueira, andar em círculos, pressionamento da cabeça contra anteparos, hiperexcitabilidade, decúbito e morte (Bagust \& Clark 1972, Narita et al. 1976, Beltrão 2000, Meyer et al. 2001, Perez et al. 2002). Os sinais neurológicos são progressivos e geralmente resultam em morte, embora casos de recuperação após curso clínico de intensidade leve ou moderada também possam ocorrer (Belknap et al. 1994, Beltrão 2000). Em animais que morrem ou são sacrificados durante a enfermidade neurológica, o vírus, e alterações histológicas podem ser detectados em várias áreas do encéfalo (Beltrão 2000, Meyer et al. 2001, Perez et al. 2002).

A exemplo de outros alfaherpesvírus, como o vírus do herpes simplex (HSV, Stroops et al., 1984) e o vírus da pseudoraiva (PRV, Babic et al. 1994, Card et al. 1994), a invasão do encéfalo pelo BoHV-5 a partir dos sítios de replicação primária ocorre através de fibras nervosas cujas terminações distribuem-se na mucosa nasal (Chowdhury et al. 1997, Lee et al. 1999). Duas vias principais de acesso ao SNC a partir da mucosa nasal têm sido sugeridas: (1) A via olfatória, através das terminações nervosas dos neurônios bipolares que inervam a mucosa olfatória e projetam para o bulbo olfatório e (2) A via trigeminal, pelos axônios dos neurônios pseudounipolares, cujos corpos celulares localizam-se no gânglio trigêmeo e projetam terminações aos núcleos sensoriais da ponte e do bulbo (Chowdhury et al. 1997, Lee et al. 1999). A cinética de invasão e a distribuição do vírus e alterações inflamatórias no encéfalo de bovinos em fases precoces da infecção sugerem que o vírus atinja o encéfalo principalmente pela via olfatória (Narita et al. 1976, Meyer et al. 2001, Perez et al. 2002). Em coelhos utilizados como modelo, o BoHV-5 também parece atingir o SNC mais precocemente e massivamente através da via olfatória (Chowdhury et al. 1997, Lee et al. 1999, Beltrão et al. 2000). Não obstante, a capacidade do BoHV-5 de atingir e estabelecer infecções latentes no gânglio trigêmeo (TG) de coelhos (Caron et al. 2002) e bovinos (Meyer et al. 2001, Vogel et al. 2003), além da deteç̧ão freqüiente de vírus ou DNA viral no tronco cerebral durante a infecção aguda e latente (Beltrão 2000, Meyer et al. 2001, Vogel et al. 2003), indicam que o transporte através de fibras nervosas que compõe o nervo trigêmeo - i.e. os ramos maxilar e oftálmico - também pode ocorrer, e potencialmente contribuir para a invasão do SNC durante a infecção aguda.

O presente estudo teve como objetivo investigar a importância das vias olfatória e trigeminal no acesso do BoHV-5 ao encéfalo de coelhos após infecção experimental. Para isso, coelhos recém-desmamados foram submetidos à ablação cirúrgica do bulbo olfatório e posteriormente inoculados com uma cepa altamente neurovirulenta do BoHV-5 pela via intranasal ou 
intraconjuntival. Observou-se que a ablação dos bulbos olfatórios previamente à inoculação preveniu a infecção e enfermidade neurológica após inoculação intranasal, mas não após inoculação no saco conjuntival. Estes resultados indicam que as duas vias podem operar no acesso do BoHV-5 ao SNC de coelhos, dependendo da via de inoculação e local da replicação primária.

\section{MATERIAL E MÉTODOS}

\section{Desenho experimental}

Coelhos recém-desmamados, submetidos ou não à ablação cirúrgica prévia dos bulbos olfatórios (BOs), foram inoculados pela via intranasal (IN) ou conjuntival (IC) com uma cepa de BoHV-5 e posteriormente monitorados quanto à replicação e excreção viral, sinais neurológicos e mortalidade. As taxas de morbidade, mortalidade e o curso clínico da enfermidade neurológica desenvolvida pelos animais dos diferentes grupos foram comparados. Animais que sobreviveram à infecção aguda foram submetidos à administração de dexametasona na tentativa de reativar possíveis infecções latentes e assim demonstrar que o vírus foi capaz de atingir o gânglio trigêmeo (TG) durante a infecção aguda.

\section{Células e vírus}

Os procedimentos de multiplicação, quantificação e isolamento de vírus de secreções nasais, oculares e tecidos foram realizados em células de linhagem de rim bovino CRIB (Flores \& Donis 1995). As células foram cultivadas em meio essencial mínimo (MEM), contendo penicilina $(1,6 \mathrm{mg} / \mathrm{L})$, estreptomicina $(0,4 \mathrm{mg} / \mathrm{L})$, suplementado com soro fetal bovino a $5 \%$. Para a inoculação, foram utilizadas alíquotas de $1 \mathrm{ml}$ do sobrenadante de cultivos celulares infectados com uma cepa brasileira de BoHV-5 (SV-507; Delhon et al. 2003), contendo $10^{8,3}$ doses infectantes para $50 \%$ dos cultivos $\left(\mathrm{DICC}_{50} / \mathrm{ml}\right.$ ).

\section{Animais, inoculação e monitoramento}

Foram utilizados 45 coelhos da raça Nova Zelândia, com idade entre 30 e 40 dias, recém-desmamados, pesando entre $700 \mathrm{~g}$ e $1,1 \mathrm{~kg}$. Após o desmame (30 dias de idade), os animais foram mantidos em gaiolas coletivas (4 a 6 animais cada), alimentados com ração e água ad libitum. Os animais foram aleatoriamente alocados em quatro grupos, correspondentes aos tratamentos utilizados: Grupo 1, submetidos à ablação cirúrgica dos $\mathrm{BOs}$ - inoculação intranasal $(\mathrm{n}=11)$; Grupo 2, controle - inoculação intranasal $(n=10)$; Grupo 3, submetido à ablação dos BOs - inoculação conjuntival $(n=12)$; Grupo 4 , controle - inoculação conjuntival $(\mathrm{n}=12)$.

Os animais dos Grupos 1 e 3 foram submetidos à ablação cirúrgica dos BOs, de acordo com metodologia descrita detalhadamente por Fonseca et al. (2004). Em resumo, os animais foram anestesiados e submetidos a tricotomia e desinfecção da pele na região entre as órbitas. $\mathrm{O}$ acesso à cavidade craniana foi realizado com o auxílio de uma broca cirúrgica de $3 \mathrm{~mm}$ de diâmetro. Os bulbos olfatórios foram localizados e aspirados em sua totalidade com o auxílio uma sonda acoplada à uma bomba de vácuo. Em um experimento preliminar, a técnica foi padronizada e alguns animais foram submetidos a eutanásia logo após a cirurgia, para se assegurar da remoção total dos bulbos olfatórios. Quatro a seis dias após o procedimento, os animais foram inoculados com BoHV-5, juntamente com os animais dos Grupos Controle (2 e 4).

Os animais dos Grupos 1 e 2 foram inoculados pela via intranasal (IN), através de aberturas dorso-laterais dos seios paranasais (protocolo adaptado por Silva et al. 1999). Para tal, os animais foram previamente anestesiados com $2 \mathrm{mg}$ de Tiletamina/Zolazepam (Zoletil, Virbac). A suspensão viral ( $1 \mathrm{ml}$ ) foi dividida e inoculada nos seios paranasais de ambos os lados (inóculo total $10^{8,3} \mathrm{DICC}_{50}$ ). Os animais dos Grupos $3 \mathrm{e}$ 4 foram inoculados pela via conjuntival (IC) com a mesma dose de vírus, através de gotejamento da suspensão viral nos sacos conjuntivais de ambos os lados. Para administração de dose e volume equivalentes evitando-se o extravasamento do inóculo, o volume foi dividido e inoculado em três momentos, com intervalos de 1 hora.

Após a inoculação, os animais foram monitorados clinicamente durante 30 dias, com três observações diárias de uma hora. 0 tempo decorrido da inoculação ao aparecimento dos sinais clínicos e as características dos mesmos foram registrados. Suabes nasais ou oculares (dependendo da via de inoculação) foram coletados a cada três dias até o dia 9pi para pesquisa de vírus. Os suabes foram drenados, centrifugados a $2000 \mathrm{x}$ g por $10 \mathrm{~min}$ e o sobrenadante $(0,5 \mathrm{ml})$ foi inoculado em monocamadas de células CRIB cultivadas em placas de 24 cavidades e submetido a três passagens de cinco dias cada, monitorando-se o aparecimento de efeito citopático (ECP). Alguns animais que apresentaram manifestações neurológicas foram submetidos à eutanásia 8 a 12 horas após o início dos sinais; outros morreram após o agravamento do quadro clínico. $O$ encéfalo dos animais que morreram ou foram submetidos à eutanásia foi coletado e as diferentes secções do SNC foram processadas para a pesquisa de vírus, conforme descrito anteriormente (Beltrão et al. 2000).

No dia 50pi, os coelhos do Grupo $1(\mathrm{n}=10)$ que sobreviveram a infecção aguda foram submetidos à administração de dexametasona (Azium, Schering Plough) na dose de $2 \mathrm{mg} / \mathrm{kg}$ durante cinco dias, via IM. Nos 12 dias seguintes, secreções nasais e oculares foram coletadas com o auxílio de suabes e submetidas ao isolamento de vírus em células CRIB, conforme descrito acima.

Todos os procedimentos de manipulação e experimentação com os animais foram realizados de acordo com as normas do COBEA (lei 6.638 de 8 maio de 1979).

\section{RESULTADOS}

O curso virológico e clínico apresentado pelos animais submetidos ou não à ablação prévia dos BOs e posteriormente inoculados com a cepa SV-507 do BoHV-5 pelas vias intranasal (IN) ou no saco conjuntival (IC) estão resumidos nos Quadros 1 e 2 . No Grupo 1 (sem BOs, inoculação IN), o vírus foi detectado em secreções nasais até o dia 6pi em todos os 11 animais e no dia 9pi em 5 deles. Apenas um animal desenvolveu sinais neurológicos, no dia 17pi, e foi submetido à eutanásia in extremis um dia após. No Grupo 2 (controle, inoculação IN) o vírus também foi detectado até o dia 6pi em todos os animais e no dia 9pi em 4 deles. Todos os animais desse grupo apresentaram apatia, depressão e sinais neurológicos como bruxismo, opistótono, andar em círculos e convulsões. Os sinais iniciaram entre os dias 5 e 10pi (média 7,5 dias) e duraram entre 8 e 72h. Alguns animais apresentaram cegueira (6/10), sialorréia (3/10) e hiperexcitabilidade. Um animal apresentou apatia e bruxismo entre os dias 8 e 10pi e se recuperou. Os demais morreram ou sofreram eutanásia in extremis 12 a 24 h após o início dos sinais.

Entre os animais do Grupo 3 (sem BOs, inoculação IC), a presença do vírus foi detectada no saco conjuntival de 10/12 animais no dia 6pi e em 3/12 no dia 9pi. Dez animais (10/12 ou $83,3 \%$ ) apresentaram sinais neurológicos característicos. Os sinais clínicos apresentados foram, em geral, muito semelhantes aos apresentados pelos coelhos do Grupo 1, porém com início mais tardio (entre os dias 9 e 15pi, média de 12,7 dias). Nos 
Quadro 1. Achados virológicos e clínicos em coelhos inoculados com o herpesvírus bovino tipo 5 submetidos ou não à ablação prévia dos bulbos olfatórios

\begin{tabular}{|c|c|c|c|c|}
\hline \multirow[t]{2}{*}{ Tratamento } & \multicolumn{2}{|c|}{ Excreção viral $^{\mathrm{a}}$ (dpi) } & Início dos & \multirow[t]{2}{*}{ Curso clínico } \\
\hline & 3 & 9 & sinais (dpi) & \\
\hline
\end{tabular}

Grupo 1. Sem bulbo olfatório - Inoculação intranasal

$\begin{array}{rrrrr}1 & + & + & - & - \\ 2 & + & + & - & - \\ 3 & + & + & + & 17 \\ 4 & + & + & + & - \\ 5 & + & + & + & - \\ 6 & + & + & + & - \\ 7 & + & + & - & - \\ 8 & + & + & - & - \\ 9 & + & + & + & - \\ 10 & + & + & - & - \\ 11 & + & + & - & -\end{array}$

Grupo 2. Controle - Inoculação intranasal

$\begin{array}{llllll}12 & + & + & +{ }^{\mathrm{b}} & 8 & \text { Bruxismo, convulsões, andar em círculos e cegueira } \\ 13 & + & + & + & 7 & \text { Bruxismo, opistótono e convulsões } \\ 14 & + & + & + & 5 & \text { Bruxismo, opistótono, convulsões, cegueira e sialorréia } \\ 15 & + & + & + & 7 & \text { Bruxismo, opistótono, convulsões, cegueira, miose } \\ 16 & + & + & + & 7 & \text { Bruxismo, opistótono, convulsões, cegueira e sialorréia } \\ 17 & + & + & - & 8 & \text { Bruxismo, opistótono, convulsões, cegueira, miose } \\ 18 & + & + & - & 10 & \text { Bruxismo e mutilação } \\ 19 & + & + & + & 10 & \text { Bruxismo, opistótono, convulsões, sialorréia } \\ 20 & + & + & + & 5 & \text { Bruxismo, opistótono, cegueira, andar em círculos } \\ 21 & + & + & - & 8 & \text { Bruxismo e apatia (recuperou-se) }\end{array}$

Grupo 3. Sem bulbo olfatório - Inoculação conjuntival

$\begin{array}{llllcl}34 & + & + & + & 14 & \text { Bruxismo, convulsões, miose } \\ 35 & + & + & - & 11 & \text { Bruxismo, opistótono, convulsões e andar em círculos } \\ 36 & + & + & - & - & - \\ 37 & + & - & - & 14 & \text { Bruxismo, opistótono, convulsões e miose } \\ 38 & + & + & - & 13 & \text { Bruxismo, opistótono, convulsões } \\ 39 & + & + & + & 14 & \text { Bruxismo, opistótono, convulsões } \\ 40 & + & + & - & 13 & \text { Bruxismo, opistótono, convulsões, cegueira e sialorréia } \\ 41 & + & + & + & 15 & \text { Bruxismo, opistótono (recuperou-se) } \\ 42 & + & + & - & 12 & \text { Bruxismo, opistótono, convulsões } \\ 43 & + & + & - & - & \text { - } \\ 44 & + & - & - & 9 & \text { Bruxismo, opistótono, incoordenação e sialorréia } \\ 45 & + & + & - & 12 & \text { Bruxismo, opistótono e convulsões }\end{array}$

Grupo 4. Controle - Inoculação conjuntival

$\begin{array}{llllll}22 & + & - & - & 11 & \text { Bruxismo, opistótono e sialorréia } \\ 23 & + & - & - & - & - \\ 24 & + & + & - & 11 & \text { Bruxismo, opistótono, excitação, estado de alerta } \\ 25 & + & + & - & - & - \\ 26 & + & + & - & 17 & \text { Bruxismo, apatia, opistótono e incoordenação } \\ 27 & + & + & - & 14 & \text { Bruxismo, opistótono, convulsões, cegueira, andar em círculos } \\ 28 & + & + & - & 20 & \text { Bruxismo, opistótono, incoordenação e convulsões } \\ 29 & + & + & + & 18 & \text { Bruxismo e apatia } \\ 30 & + & - & - & 12 & \text { Bruxismo, opistótono, convulsões, cegueira, andar em círculos } \\ 31 & + & + & - & 13 & \text { Bruxismo, opistótono, convulsões e sialorréia } \\ 32 & + & - & - & 19 & \text { Bruxismo, opistótono, convulsões e miose } \\ 33 & + & - & - & 18 & \text { Bruxismo, nistagmo, andar em círculos, opistótono e convulsões }\end{array}$

a Vírus em secreções nasais ou oculares, de acordo com a via de inoculação.

b Morreram antes da coleta.

animais do grupo 4 (controle, inoculação IC), replicação viral no saco conjuntival foi detectada até o dia 6pi em 7/12 animais e no dia 9pi em um animal. Dez animais $(83,3 \%$ ) apresentaram manifestações neurológicas de curso e características semelhantes ao grupo anterior, com início entre os dias 11 e 20pi (média 15,3 dias). Dentre os animais que desenvolveram sinais neurológicos evidentes, apenas dois (um do Grupo 1; outro do Grupo 3) recu- peraram-se, após um curso de intensidade leve a moderada de dois a três dias; os demais morreram ou foram sumetidos à eutanásia. Nestes animais, a presença do vírus foi detectada em diferentes secções do cérebro submetidas ao isolamento em cultivo celular (dados não mostrados).

A administração de dexametasona no dia 50pi aos 10 coelhos do Grupo 1 que sobreviveram à infecção aguda foi seguida 


\begin{tabular}{|c|c|c|c|c|c|}
\hline Grupo & Tratamento & Número & Morbidade & $\begin{array}{l}\text { Início dos sinais } \\
\text { dpi (média) }\end{array}$ & Mortalidade \\
\hline 1 & $\begin{array}{l}\text { Ablação dos BOs + } \\
\text { inoculação intranasal }\end{array}$ & 11 & $1(9,1 \%)$ & 17 & $1(9,1 \%)$ \\
\hline 2 & $\begin{array}{c}\text { Controle }+ \\
\text { inoculação intranasal }\end{array}$ & 10 & $10(100 \%)$ & $5-10(7,5)$ & $9(90 \%)$ \\
\hline 3 & $\begin{array}{c}\text { Ablação dos BOs + } \\
\text { inoculação conjuntival }\end{array}$ & 12 & $10(83,3 \%)$ & $9-15(12,7 \%)$ & 9 (75\%) \\
\hline 4 & $\begin{array}{c}\text { Controle }+ \text { inoculação } \\
\text { conjuntival }\end{array}$ & 12 & $10(83,3 \%)$ & $11-20(15,3)$ & $10(83,3 \%)$ \\
\hline
\end{tabular}

de excreção viral em 8 deles (80,0\%). Quatro animais excretaram vírus em secreções nasais e oculares, três excretaram apenas nas secreções nasais e um apenas na conjuntival. A excreção foi detectada já no dia 1 pDx em um animal e foi verificada até o dia 11 pDx em dois animais. Três animais excretaram vírus apenas durante um dia; três animais excretaram durante dois dias; e nos demais a excreção viral foi detectada em quatro e oito dias, respectivamente.

\section{DISCUSSÃO}

Os resultados dos experimentos demonstram que tanto a via olfatória como a trigeminal podem servir de acesso para o BoHV-5 invadir o SNC de coelhos após inoculação experimental. A rota que contribui para a invasão e replicação viral maciça que ocorre durante a infecção neurológica aguda depende da via de inoculação e parece operar com diferentes cinéticas. A inoculação intranasal resulta em transporte rápido com conseqüiente invasão e disseminação do vírus no encéfalo, principalmente pela via olfatória. Isso foi demonstrado pela redução drástica na morbidade e mortalidade no grupo de animais sem BOs (Grupo 1), em comparação com o Grupo Controle (Grupo 2). 0 desenvolvimento de doença neurológica em um animal deste grupo, no entanto, indica que outra via também pode ser utilizada pelo BoHV-5 para atingir o encéfalo após replicação nasal. Por outro lado, a inoculação IC resulta em transporte viral eficiente ao cérebro, porém com cinética tardia em relação ao transporte pela via olfatória após inoculação IN. A ablação prévia dos bulbos olfatórios não interferiu com a cinética e curso da enfermidade neurológica nesse grupo, demonstrando que a invasão do SNC ocorreu por outra via, que não a olfatória.

A redução drástica da morbidade e mortalidade após inoculação IN no grupo de coelhos submetidos à ablação dos BOs (Grupo 1) demonstrou que a via olfatória constitui-se na principal rota de acesso ao SNC, confirmando evidências anteriores em bovinos (Narita et al. 1976, Perez et al. 2002) e coelhos (Chowdhury et al. 1997, Beltrão et al. 2000, Perez et al. 2002). A ocorrência de infecção neurológica em um dos animais deste grupo, no entanto, indica que uma via alternativa pode também ser utilizada pelo vírus para atingir o cérebro. Já foi demonstrado que tanto a via trigeminal (ramo maxilar do trigêmeo) como a rota olfatória podem servir de acesso ao SNC para o vírus do herpes simplex (HSV) e o vírus da pseudoraiva (PRV) em ratos e suínos, respectivamente (McLean et al. 1989, Babic et al. 1994).
Estudos realizados por Lee et al. (1999) falharam em demonstrar infecção significativa pelo BoHV-5 em neurônios do TG de coelhos que sofreram eutanásia até oito dias após inoculação IN. Antígenos virais também não foram detectados nos núcleos da ponte e do bulbo em coelhos examinados nos dias subseqüentes. Por isso, os autores sugeriram que a via trigeminal não é importante na invasão do SNC de coelhos após inoculação IN, provavelmente devido a uma incapacidade do vírus de infectar eficientemente as terminações do ramo maxilar do nervo trigêmeo que se distribuem na mucosa respiratória (Lee et al. 1999).

Vários estudos anteriores demonstraram que o TG constituise no principal sítio de infecção latente pelo BoHV-5, tanto nos seus hospedeiros naturais (Meyer et al. 2001, Vogel et al. 2003), como em coelhos infectados experimentalmente (Caron et al. 2002). Adicionalmente, pelo menos três evidências no presente estudo fortalecem a hipótese de transporte pela via trigeminal a partir da cavidade nasal: (1) Antígenos do BoHV-5 foram detectados por imunoistoquímica no TG de três animais que morreram ou sofreram eutanásia in extremis nos dias 11 e 12pi (dados não mostrados); (2) O curso e cinética da enfermidade neurológica no animal sem BOs que desenvolveu doença neurológica após inoculação IN (Grupo 1) foram semelhantes aos inoculados pela via IC; a inoculação por esta via provavelmente resulta em trasporte via trigeminal; e (3) A administração de dexametasona nos animais sem BOs resultou em reativação e excreção viral nas secreções nasais e oculares, demonstrando inequivocamente que o vírus foi capaz de atingir o TG durante a infecção aguda. Esses resultados indicam que o BoHV-5 pode ser transportado também pela via trigeminal. Essa via, no entanto, provavelmente não seja importante na patogenia da doença neurológica aguda após inoculação IN, por duas razões: (1) A quantidade de vírus que atinge o TG pela via trigeminal após inoculação IN seria insuficiente para assegurar a replicação e posterior invasão do encéfalo a partir daí - mas suficiente apenas para o estabelecimento de infecção latente, como foi demonstrado pela reativação e excreção viral após tratamento com dexametasona; e (2) A invasão e replicação viral maciça do SNC que ocorrem pela via olfatória, e o conseqüiente desenvolvimento de doença neurológica e morte, provavelmente precedem a invasão que estaria em curso pela via trigeminal. A diferença no tempo de início dos sinais clínicos nos grupos inoculados pela via IN (média 7,5 dias) versus IC (média 12,7 dias), e o início tardio dos sinais no animal 
sem BOs inoculado pela via IN (17 dias), reforçam esta hipótese e podem explicar a falha em detectar o vírus no TG nos dia 8 após inoculação IN (Lee et al. 1999). A probabilidade de se detectar vírus ou antígenos virais no TG após inoculação IN aumentaria nos animais que desenvolvem a doença neurológica mais tardiamente, como observado no presente estudo.

Os resultados da inoculação do BoHV-5 pela via conjuntival, em animais dos Grupos 3 e 4 (com e sem BOs), confirmaram que o vírus pode utilizar outra via, que não a olfatória, para invadir o SNC de coelhos. A via de acesso utilizada provavelmente foi o ramo oftálmico do nervo trigêmeo, cujas terminações distribuem-se sob a mucosa conjuntival (Babic et al. 1994, Card et al. 1994, Stroop et al. 1994). O transporte do vírus ao SNC provavelmente envolveu várias etapas: (1) Replicação na mucosa conjuntival e penetração nas terminações nervosas do ramo oftálmico; (2) Transporte retrógrado pelo nervo oftálmico até os corpos neuronais no gânglio trigêmeo; (3) Replicação nos neurônios do TG e/ou transporte anterógrado até os neurônios de segunda ordem nos núcleos pontinos e bulbares; e (4) Transporte e disseminação aos neurônios de terceira ordem no cerebelo e tálamo e daí aos neurônios de quarta ordem no córtex cerebral. Esses resultados contrariam estudos anteriores que indicavam que a via trigeminal não é importante para a invasão do SNC, devido ao fato do vírus não ser transportado eficientemente no sentido anterógrado, do TG para os núcleos da ponte e bulbo (Lee et al. 1999). Os resultados do presente experimento sugerem que o vírus provavelmente seja transportado eficientemente no sentido anterógrado, do TG em direção ao SNC, Após inoculação IN, no entanto, isso não poderia ser demonstrado porque a invasão maciça que ocorre pela via olfatória antecederia a invasão do SNC pela via trigeminal. Nos animais do Grupo 1, é possível que a quantidade de vírus que atingiu o TG tenha sido suficiente para o estabelecimento de infecção latente, porém insuficiente para a invasão do SNC a partir do TG. Nos animais dos Grupos 3 e 4, a quantidade de vírus que foi transportada pela via trigeminal até os corpos neuronais situados no gânglio provavelmente foi maior, resultando em replicação e invasão dos núcleos da ponte e do bulbo e daí para as outras regiões do encéfalo. Diferenças de tropismo pelas terminações dos neurônios localizadas no epitélio respiratório e conjuntival, assim como diferenças no transporte retrógrado e anterógrado através dos axônios e/ou dendritos também podem explicar as diferenças na eficiência e/ou cinética de transporte dos alfaherpesvírus em diferentes vias nervosas (Babic et al. 1994, Card et al. 1994, Chowdhury et al. 1997, Lee et al. 1999).

Em resumo, os resultados indicam que tanto a via olfatória como a trigeminal podem servir de acesso para o BoHV-5 invadir o cérebro de coelhos após infecção experimental. A replicação nasal resulta em transporte rápido e eficiente pela via olfatória e desenvolvimento precoce de infecção e doença neurológica. $\mathrm{O}$ transporte do vírus pela via trigeminal também pode ocorrer, porém parece não contribuir para a patogenia da doença aguda, pois é menos eficiente e tardio. A inoculação e replicação viral na mucosa ocular também resultam em transporte e invasão eficientes ao SNC. Essa invasão, porém, é mais tardia do que a que ocorre pela via olfatória após inoculação IN, e provavelmente ocorre pela via trigeminal. Também foi demonstrado que a integridade da via olfatória não é necessária para o estabelecimento e reativação da infecção latente pelo BoHV-5 em coelhos. Esses resultados fornecem importantes informações sobre a patogenia da infecção neurológica pelo BoHV-5. No entanto, os experimentos foram realizados em um modelo experimental, e como tal necessitam investigações posteriores para se verificar se mecanismos semelhantes ocorrem nos seus hospedeiros naturais.

Agradecimentos.- Ao Diretor do Biotério Central da UFSM, Médico Veterinário Silvandro Noal pela cedência de alojamento dos animais durante o experimento. Aos bolsistas de iniciação científica pelo auxílio com a manipulação e monitoramento dos animais. Ao CNPq pelos recursos e bolsas (Eduardo F. Flores [301666/2004-0] e Rudi Weiblen [520011/95], são bolsistas PQ do CNPq e Diego G. Diel e Soraia F. Souza, são bolsistas do do $\mathrm{CNPq}$ ).

\section{REFERÊNCIAS}

Babic N., Mettenleiter T.C., Ugolini G., Flamand A. \& Coulon P. 1994. Propagation of pseudorabies virus in the central nervous system of the mouse after intranasal inoculation. Virol. 204:616-625.

Bagust T. J. \& Clark L. 1972. Pathogenesis of meningoencephalitis produced in calves by infectious bovine rhinotracheitis herpesvirus. J. Comp. Path. 82:375-383.

Belknap E.B., Collins J.K., Ayers V.K. \& Schultheiss P.C. 1994. Experimental infection of neonatal calves with neurovirulent bovine herpesvirus type 5 (BHV-5). Vet. Pathol. 31:358-365.

Beltrão N. 2000. Herpesvírus bovino tipo 5 (BHV-5): infecção experimental de bovinos e utilização de coelhos como modelo. Dissertação de Mestrado, Universidade Federal de Santa Maria, Santa Maria, RS. 54p.

Beltrão N., Flores E.F., Weiblen R., Silva A. M., Roehe P.M. \& Irigoyen L.F. 2000. Infecção e enfermidade neurológica pelo herpesvírus bovino tipo 5 (BHV-5): coelhos como modelo experimental. Pesq. Vet. Bras. 20:144-150.

Card J. P., Rinaman L., Schwaber J.S., Miselis R.R., Whealy M.E., Robbins A.K. \& Enquist L.W. 1994. Neurotropic properties of pseudorabies virus: transneuronal passage in the rat central nervous system. J. Neurosci. 10:1974-1994.

Caron L., Flores E.F., Weiblen R. Scherer, C.F.C., Irigoyen L.F., Roehe P.M., Odeon A. \& Sur J-H. 2002. Latent infection by bovine herpesvirus type5 in experimentally infected rabbits: virus reactivation, shedding and recrudescence of neurological disease. Vet. Microbiol. 84(4):285-295.

Carrillo B.J., Pospischil A. \& Dahme E. 1983. Pathology of a bovine viral necrotizing encephalitis in Argentina. Zbl. Vet. Med. B 30:161-168.

Chowdhury S.I., Lee B.J., Mosier B.J., Sur J-H., Osorio F.A., Kennedt G. \& Weiss M.L. 1997. Neuropathology of bovine herpesvirus type 5 (BHV-5) meningoencephalitis in a rabbit seizure model. J.Comp.Pathol. 117:295310.

Delhon G., Moraes M. P., Lu Z., Flores E.F., Weiblen R. \& Rock D. 2003. Genome of bovine herpesvirus type 5. J.Virol. 77:10339-10347.

Flores E.F. \& Donis R.1995. Isolation of a mutant MDBK cell line resistant to bovine virus diarrhea virus (BVDV) due to a block in viral entry. Virol. 208:565-575.

Fonseca E.T., Diel D.G., Souza S.F., Gomes K. Mazzanti A., Weiblen R. \& Flores E.F. 2004. Ablação dos bulbos olfatórios em coelhos. XIX JAI Jornada Acadêmica Integrada, UFSM, 19-21 outubro.

Lee B.J., Weiss M.L., Mosier B.J. \& Chowdhury S.I. 1999. Spread of bovine herpesvirus type 5 (BHV-5) in the rabbit brain after intranasal inoculation. J. Neurovirol. 5:474-484.

McLean, J.H. Shipley M.T. \& Bernstein D.I. 1989. Golgi-like, transneuronal retrograde labeling with CNS injections of herpes simplex virus type 1 . Brain Res. Bull. 22:867-881. 
Meyer G., Lemaire M., Ros C., Belak K., Gabriel A., Cassart D., Coignoul F., Belak S. \& Thiry E. 2001. Comparative pathogenesis of acute and latent infections of calves with bovine herpesvirus types 1 and 5. Arch. Virol. 146:633-652.

Narita M., Inui S., Namba K. \& Shimizu Y. 1976. Trigeminal ganglionitis and encephalitis in calves intranasally inoculated with infectious bovine rhinotracheitis virus. J. Comp. Path. 86:93-100.

Perez S.E, Bretschneider C., Leunda M.R., Osorio F.A., Flores E.F. \& Odeón A.C. 2002. Primary infection, latency and reactivation of bovine herpesvirus type 5 (BHV-5) in the bovine nervous system. Vet. Pathol. 39:437-444

Roizman B. 1992. The family Herpesviridae: an update. Arch. Virol. 123:425-449.

Salvador S.C., Lemos R.A.A., Riet-Correa F., Roehe P.M., Osorio A.L.A.R. 1998. Meningoencephalitis in cattle caused by bovine herpesvirus- 5 in Mato Grosso do Sul and São Paulo. Pesq.Vet.Bras. 18:76-83.
Silva A.M., Flores E.F., Weiblen R., Canto M.C., Irigoyen L.F., Roehe P.M. \& Sousa R.S. 1999. Pathogenesis of meningoencephalitis in rabbits by bovine herpesvirus type-5 (BHV-5). Revta Microbiol., São Paulo, 30:22-31.

Stroop W.J., Rock D.I. \& Fraser N.W.1984. Localization of herpes simplex virus in the trigeminal and olfactory system of the mouse central nervous system during acute and latent infection by in situ hybridization. Lab.Invest. 51:27-38.

Vogel F.S.F., Caron L., Flores E.F., Weiblen R., Winkellmann E.R., Mayer S.V. \& Bastos G. 2003. Distribution of bovine herpesvirus type 5 (BHV-5) DNA in the central nervous system of latently, experimentally infected calves. J. Clin. Microbiol. 41:4512-4520.

Vogel F.S.F., Lima M., Flores E.F., Weiblen R., Winkellmann E.R., Mayer S.V., Mazzutti K. C., \& Arenhart S. 2004. Replicação e excreção viral durante a infecção aguda e após a reativação da latência induzida por dexametasona em bezerros inoculados com os herpesvírus bovinos tipo 1 (BHV-1) e 5 (BHV-5). Ciência Rural, Santa Maria, 34:1619-1621. 